\title{
Antihyperlipidaemic and Antioxidant Potential of Fermented Citrullus vulgaris Seeds (Thunb.) on Tyloxapol-induced Hyperlipidaemic Rats: A Comparison With Fluvastatin
}

\author{
Aderonke R. Ayo-Lawal ${ }^{1,2}$, Omolaja Osoniyi ${ }^{2}$ \& Akindele J. Famurewa ${ }^{1}$ \\ ${ }^{1}$ National Centre for Technology Management (NACETEM), Obafemi Awolowo University, Ile-Ife, Osun State, \\ Nigeria \\ ${ }^{2}$ Biochemistry Department, Obafemi Awolowo University, Ile-Ife, Osun State, Nigeria \\ Correspondence: Aderonke R. Ayo-Lawal, NACETEM, PMB 012, Obafemi Awolowo University, Ile-Ife, Osun \\ State, Nigeria. Tel: 234-70-345-846-45. E-mail: ronke_ode@yahoo.com
}

Received: April 14, 2015 Accepted: May 29, 2015 Online Published: June 16, 2015

doi:10.5539/jfr.v4n4p110 URL: http://dx.doi.org/10.5539/jfr.v4n4p110

\begin{abstract}
Globally fermented foods form an integral part of the staple diet of people. Fermented Citrullus vulgaris (FCV) (ogiri) seeds is a nutritious natural fermented condiment that features frequently in West African diets as a spice. This study investigated the antihyperlipidaemic potential of this condiment in tyloxapol-induced hyperlipidaemic rats with reference to that of fluvastatin, a standard antilipidaemic drug. The antioxidant potential of the condiment was also examined using different relevant in vitro assays. Albino rats were divided into six groups $(\mathrm{n}=5)$, based on the diet and treatment received. The groups were standard feed (control); FCV supplemented feed; standard feed with tyloxapol administered at the end of the experimental period (tyloxapol control); FCV supplemented feed and tyloxapol at the end of the experimental period; standard feed with fluvastatin sodium ( $40 \mathrm{mg} / \mathrm{kg}$ and $80 \mathrm{mg} / \mathrm{kg}$ body weight separately) followed by tyloxapol. The results revealed that administration of tyloxapol induced significant $(\mathrm{p}<0.05)$ increase in total-cholesterol $(\mathrm{TC})$, low density lipoprotein cholesterol (LDL-C) and triglyceride (TG). These lipid increases were significantly mitigated in groups initially pre-fed with supplemented FCV feed. Plasma TC decreased by $69.38 \%(\mathrm{p}<0.05)$; TG by $80.58 \%(\mathrm{p}<0.05)$; LDL-C by $7.80 \%(\mathrm{p}<0.05)$ and high density lipoprotein cholesterol (HDL-C) levels increased by $78.61 \%(\mathrm{p}<0.05)$. FCV showed appreciable antioxidant activities in vitro in a dose dependent manner. Histomorphological examination of the liver suggested that the FCV possessed hepatoprotective potential. These results suggest that FCV consumption may be a possible dietary measure for the control of dyslipidaemia.
\end{abstract}

Keywords: fermented Citrullus vulgaris, Ogiri, fluvastatin, HDL-C, hyperlipidaemia, LDL-C, total-cholesterol, triglyceride, tyloxapol

\section{Introduction}

Lipid profile disorders are among the most common metabolic diseases occurring in humans and are a risk index of coronary heart disease (Edem, 2002; O. B. Ajayi \& D. D. Ajayi, 2009). High concentrations of low density lipoprotein (LDL) and lower concentrations of functional high density lipoprotein (HDL) are strongly associated with cardiovascular disease because it promotes atheroma development leading to atherosclerosis. Strong correlations have been shown to exist between increased plasma total cholesterol (TC), LDL-cholesterol and increased incidence of coronary heart disease (Edionwe \& Kies, 2009; Kamisah et al., 2005; Lewington et al., 2007). The ratios of TC/HDL-cholesterol, LDL-Cholesterol/HDL-cholesterol and atherogenic index are predictors of coronary risk (National cholesterol education program, 1994). Meanwhile, the changes in eating habits including high fat and low fiber diets increased also the risk of obesity and overweight. Risk of these diseases increases steadily with increasing the values of body mass index (BMI) or food efficiency ratio (FER).Although significant strides have been made in the understanding and management of lipid disorders using synthetic medicines, the disease and its related conditions are still increasing. Many unwanted side effects of long-term use of many of the hypolipidaemic drugs have been frequently reported and many are still reportedly expensive for a lot of people in the third world (Ngoc et al., 2008; Rosebaum et al., 2012; Grundy, 2013; Sultan \& Hynes, 2013), thus developments of novel approaches from food, herbs, etc to battle the world 
epidemic of hyperlipidaemia still remain relevant (Damjana \&Katalin, 2010). Efforts to develop effective and better hypolipidaemic drugs had led to the exploration of active substances in natural agents. Preparations from plants and plants products are frequently considered to be less toxic, less expensive and have fewer side-effects than synthetic drugs (Odetola et al., 2006).

Fermented foods and beverages form major part of the human diet all across the globe. They are prepared by using indigenous knowledge on locally available raw materials from plant or animal sources. Micro-organisms transform these raw materials both biochemically and organoleptically into edible products that are culturally acceptable to the maker and consumer. Fermentation technologies play an important role in ensuring the food security of millions of people around the world, particularly the marginalized and vulnerable groups (Agriculture and Consumer Protection (ACP)).Good nutrition is one of the basic human rights which must be satisfied in order to have a healthy population that can promote development. It therefore becomes important to balance the relationship between food, nutrition and health (Akinyele \& Oloruntoba, 2013). In recent years, functional foods including fermented foods have attracted much interest to prevent nutrition-related diseases such as hyperlipidemia and weight gain. Nutritional as well as health-promoting benefits of many of the fermented foods have been well documented (ACP; Steinkraus, 1995). It has been reported for instance, that the product of industrial fermentation of wheat germ, possesses unique cancer-fighting characteristics, as well as prevention of chemical carcinogenesis, and some autoimmune conditions (Boros, Nichelatti, \& Shoenfeld, 2005).

Ogiri is an oily paste produced generally from fermentation of oil-rich seeds. Ogiri-egusi is a food condiment prepared traditionally by uncontrolled solid state fermentation of melon seeds (Citrullus vulgaris) (Achi, 2005; Akinyele and Oloruntoba, 2013) and consumed within the West African countries (Odunfa, 1981; Achi, 2005).

This study is aimed at investigating the lipid-lowering potential of fermented Citrullus vulgaris, a popular soup condiment in Africa with reference to the standard lipid-lowering drug - fluvastatin in rats. This is with a view to establishing its use as a possible alternative in therapeutic management of hyperlipidaemia and associated conditions.

\section{Materials and Methods}

\subsection{Condiment Fermentation}

Ogiri was prepared in the traditional way using dried melon seeds. The shells (husks) were removed; they were sorted to remove grit, dirt and decomposing seeds; and thereafter rinsed with warm water $\left(35^{\circ} \mathrm{C}\right)$ twice. The seeds were boiled for about one hour with ten times its volume of water. The boiled water was then drained and replaced by cold water and boiled again for about 6 hours to complete softness. At this stage, the transparent inner seed coats (tegmen) were easily removed. The pulpy melon seeds were then wrapped in Thaumatococcus daniellii leaves in different packets and cooked again for about 2-3 hours. Water and oil drained off from the wrapped pulp. The packets were placed in earthenware pots and covered with Thaumatococcus daniellii leaves. This provided low oxygen tension. The seeds were left to ferment for 5 days. The fermented product was then ground with stone mortar and pestle to almost a smooth paste. The fermented mash was ogiri.

\subsection{Preparation of Ogiri-Supplemented Feed (OSF)}

Feeds supplemented with ogiri was prepared by thoroughly mixing weighed condiment and standard rodent feed in a ratio 1:4 respectively to give a twenty percent $(20 \%)(\mathrm{w} / \mathrm{w})$ supplemented feed. The feed was pelletized by adding few drops of water, and passed through a roller to cake; and thereafter placed in the oven set at about $40^{\circ} \mathrm{C}$ for drying and caking. Feeds were prepared prior to usage for stability and to avoid storage for a long time.

\subsection{Chemicals}

Tyloxapol (Triton WR 1339) was obtained from Sigma Chemical Company, St. Louis Missouri, USA. Diagnostic kits for cholesterol, triglycerides and high-density lipoprotein (HDL) deternimations were purchased from Randox Laboratories, Antrim, United Kingdom. Fluvastatin sodium and all other reagents were of analytical grade and the purest quality available.

\subsection{Experimental Animals \& Feed Composition}

Animal house with standard animal cages and maintained at $26-29^{\circ} \mathrm{C}$ with a 12 hours light-dark cycle was used for the experiment. Rats weighing between 75 and $110 \mathrm{~g}$ (bothsexes), were acclimatized for 2 weeks before the commencement of the experiment. Animals were fed on standard laboratory chow purchased from Bendel Feeds and Flour Mills limited, Benin Road, Ewu, (EdoState, Nigeria) and contained 14.5\% crudeprotein, $4.8 \%$ crude fat, $7.2 \%$ crude fiber, $8 \%$ crude ash, $0.62 \%$ Phosphate, $0.33 \%$ available Phosphorus, $0.6 \%$ lysine, $0.29 \%$ Methionine, $0.52 \%$ Methionine + Cystine, (8,000 I.U Vitamin A, 2,400 I.U Vitamin $\mathrm{D}_{3}, 15 \mathrm{mg}$ Vitamin E, $4 \mathrm{mg}$ 
Vitamin $\mathrm{B}_{2}, 50 \mathrm{mg}$ Vitamin $\mathrm{C}, 30 \mathrm{mg}$ Manganeze, $30 \mathrm{mg}$ Zinc, $0.15 \%$ Sodium) per $\mathrm{Kg}$ feed. After acclamitization, rats were randomly sorted into six groups of five animals each.

\subsection{Experimental Animal Groupings}

Group A served as the control group and received standard feed (no treatment). Group B received ogiri-supplemented feed (OSF) only; group $\mathrm{C}$ was fed standard feed, and tyloxapol administered after the experimental period (tyloxapol control), D received OSF, and tyloxapol administered after the experimental period; groups $\mathrm{E}$ and $\mathrm{F}$ received standard feed, tyloxapol administered after the experimental period and fluvastatin sodium $40 \mathrm{mg} / \mathrm{kg}$ and $80 \mathrm{mg} / \mathrm{kg}$ body weight respectively. Tyloxapol was administered to groups C, D, $\mathrm{E}$ and $\mathrm{F}$ as described above at the end of the six weeks experimental period. Weekly weight change was monitored in rats.

\subsection{Administration of Tyloxapol}

At the end of the six weeks experimental period, animals were deprived of food for 24-hours, after which hyperlipidaemia was induced by a single intraperitoneal injection of tyloxapol $250 \mathrm{mg} / \mathrm{kg}$ body weight of rats (Ansarullah et al., 2009) to groups C, D, E and F mentioned above.

\subsection{Administration of Fluvastatin Sodium}

Two doses of the drug ( $40 \mathrm{mg}$ and $80 \mathrm{mg}$ per body weights of rats) were administered 12-hours after injection of tyloxapol to groups $\mathrm{E}$ and F orally by intubation. Rats were left for another $12 \mathrm{hrs}$ before sacrifice.

\subsection{Sample Collection}

48-hrs after the end of feed regimen (i.e. 12-hrs after fluvastatin administration), rats in all the groups were sacrificed by cervical dislocation. Blood samples were withdrawn from fasted rats by cardiac puncture using needles and syringes into heparinised bottles. Blood samples were centrifuged with a bench centrifuge at 3000 revolution per minute for 15 minutes. Plasma samples used for the assays were separated. Rats' livers were also removed.

\subsection{Preparation of Liver Homogenates}

Liver samples were washed with normal saline and blotted dry with paper towels. $1 \mathrm{~g}$ each was homogenized in $10 \mathrm{ml}$ of $0.25 \mathrm{M}$ sucrose solution to give $10 \%(\mathrm{w} / \mathrm{v})$ homogenates.

\subsection{Lipid Profile Estimation}

Plasma triglycerides (TG) and total cholesterol (TC) levels were assayed using commercial kits (Randox Laboratories). The high density lipoprotein-cholesterol (HDL) was measured using the enzymatic colorimetric method. After centrifugation at $3000 \mathrm{~g}$ for 10 minutes at $25^{\circ} \mathrm{C}$, the clear supernatant contained the HDL fraction, which was assayed for cholesterol using a Randox kit. Low density lipoprotein-cholesterol (LDL-C) was calculated using the formula of Friedwald et al. (Friedwald, Levy \& Fredicksm, 1972).

\subsection{In vitro Antioxidant Assays}

In order to ascertain the antioxidant potentials of the condiment, various standard antioxidants assays are used. Standard in vitro methods used include: 2,2-Diphenyl-1- picrylhydrazyl (DPPH) free radical scavenging assay (Blois, 1958), nitric oxide radical inhibition activity (Marcocci, Packer, \& Droy-Lefaix, 1994), anti lipid peroxidation assay (Nabasree \& Bratati, 2002), ascorbic acid equivalent (Benzie\& Strain, 1999) methods. All the assays were carried out in triplicate and average values calculated.

\subsection{Histomorphological Investigation}

Histomorphological investigation was performed at the Department of Anatomy and Cell Biology, Obafemi Awolowo University. The procedure involved fixing the liver tissue in $10 \%$ formal saline and processing via paraffin wax embedding and staining with Hematoxylin and Eosin method of Drury and Wallington (Drury \& Wallington, 1980).

\subsection{Statistical Analysis}

Statistical evaluation of the data was done using Graph Pad Prism version 5.0 for Windows, Graph Pad Software, San Diego California USA (Ansarullah et al., 2009). The difference between groups was analyzed by one - way analysis of variance (ANOVA) followed by Bonferroni's Multiple Comparison Test with 5\% level of significance $(\mathrm{P}<0.05)$ considered significant. Values are expressed as Mean \pm SEM (Standard Error of Mean). 


\section{Results}

\subsection{Average Weight Change}

A different growth pattern was observed between the group of rats fed standard rodent feed and OSF. Average weight gained throughout the experimental period are as depicted in Figure 1. Obviously tyloxapol and fluvastatin had no impact on the animal weight being experimental end points treatments. From the figure, it follows that continuous feeding of rats with the condiment for six weeks resulted in improved growth evidenced by moderate weight gain.

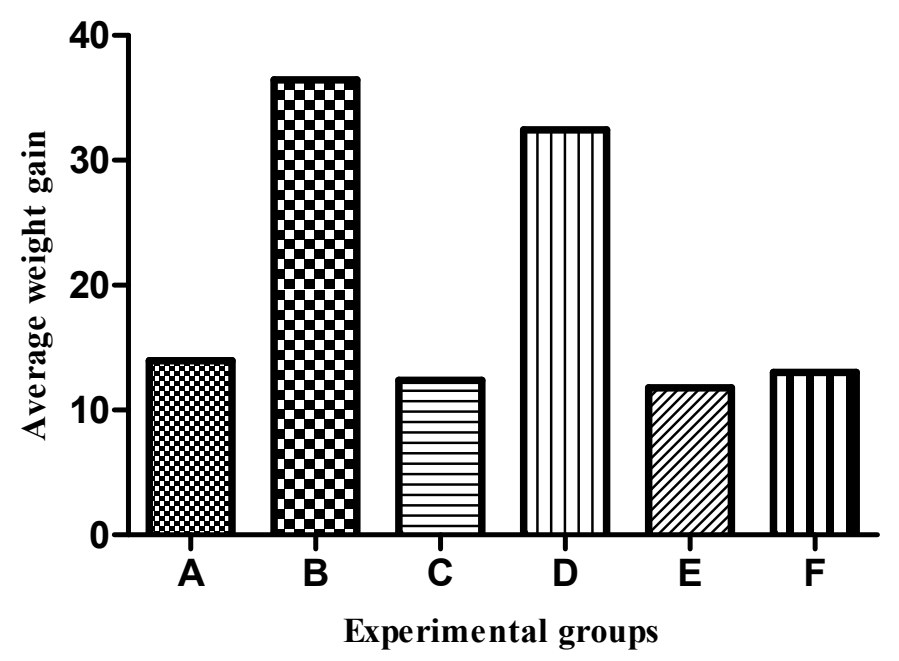

Figure 1. Graph of average mean weight of rats (A-F are as described in section 2.5)

(A: Standard feed (control); B: OSF only; C: Standard feed + Tyloxapol; D: OSF + Tyl; E: Standard feed + Tyloxapol + Fluvastatin (40 mg/body weight); F: Standard feed + Tyloxapol + Fluvastatin ( $80 \mathrm{mg} /$ body weight)

\subsection{Plasma Lipid Profile}

The plasma lipid profile analyses revealed a significant increase $(P<0.05)$ in TC, LDL-C $(67.27 \%)$ and TG in tyloxapol-treated rats (Group C). Ogiri-supplemented feed significantly $(\mathrm{P}<0.05)$ mitigated the increment when + and $*$ are compared in figure 2 . The condiment induced statistically significant $(\mathrm{P}<0.05)$ hypocholesterolemic effect compared with fluvastatin at both concentrations used in this study. OSF mitigated increased TG due to tyloxapol administration when + and * are compared in Figure $3.80 \mathrm{mg} / \mathrm{kg}$ body weight fluvastatin showed a competitive hypotriglyceridaemic activity with the condiment (Figure 3), as both are statistically insignificant at $P<0.05$. As shown in figure 4, OSF significantly $(\mathrm{P}<0.01)$ mitigated increased LDL-C due to tyloxapol administration when + and $*$ are compared. This activity was much higher than what was observed at both concentrations of fluvastatin. FCV yielded a statistically significant reduction $(\mathrm{P}<0.05)$ in LDL-C. Tyloxapol induced a significant $(\mathrm{P}<0.05)$ reduction in plasma HDL-C while OSF significantly $(\mathrm{P}<0.01)$ induced increased HDL-C in pre-fed rats (Figure 5). 


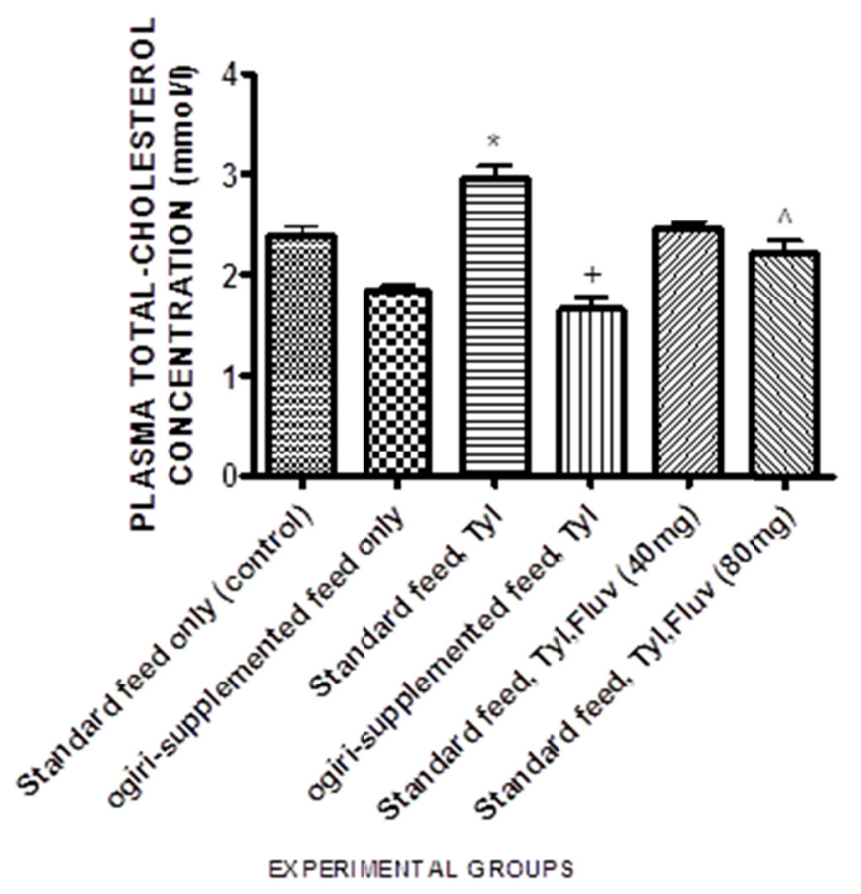

Figure 2. Graph showing the effect of rat feed and treatment(s) on plasma TC concentration following tyloxapol-induced hyperlipidaemia. $\mathrm{n}=5$. (Tyl- Tyloxapol; Fluv-Fluvastatin sodium, TC- Total Cholesterol)

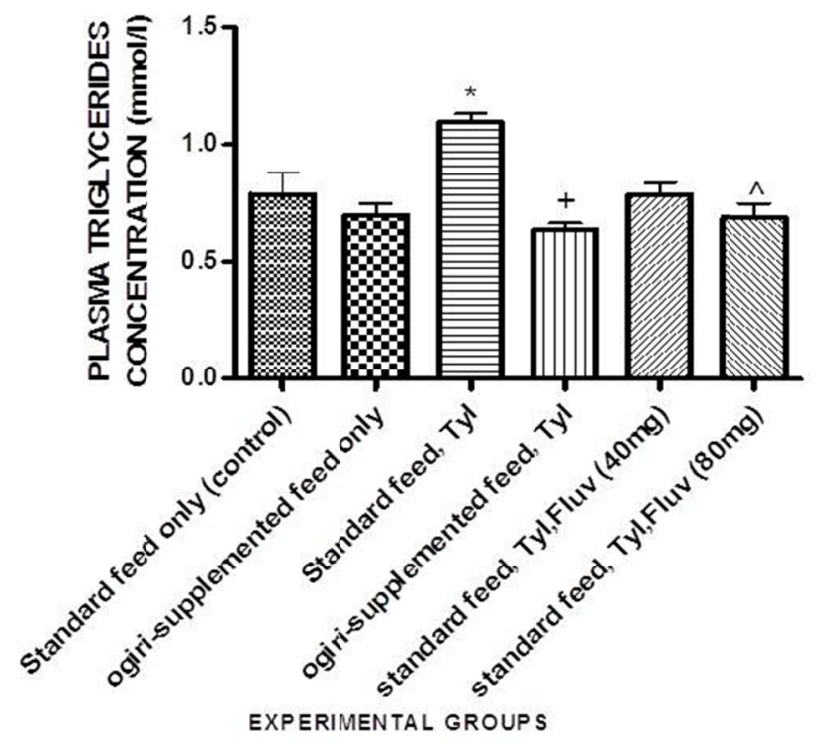

Figure 3. Graph showing the effect of rat feed and treatment(s) on plasma TG concentration following tyloxapol-induced hyperlipidaemia. $\mathrm{n}=5$. (Tyl- Tyloxapol; Fluv-Fluvastatin sodium, TG- Triglycerides) 


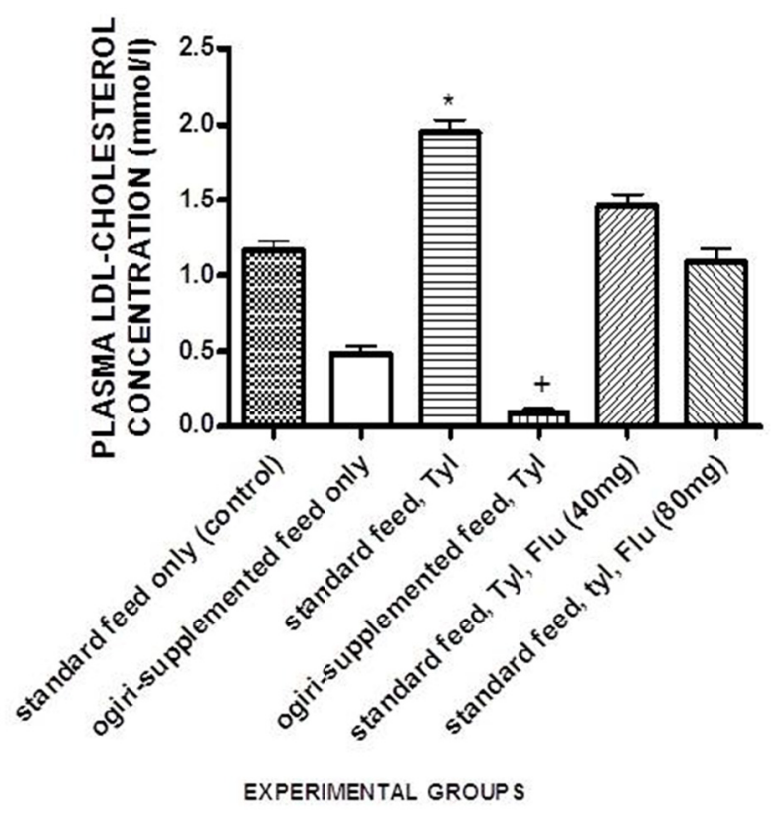

Figure 4. Graph showing the effect of rat feed and treatment(s) on plasma LDL-C concentration following tyloxapol-induced hyperlipidaemia. $\mathrm{n}=5$. (Tyl- Tyloxapol; Fluv-Fluvastatin sodium, LDL-C- low density lipoprotein cholesterol)

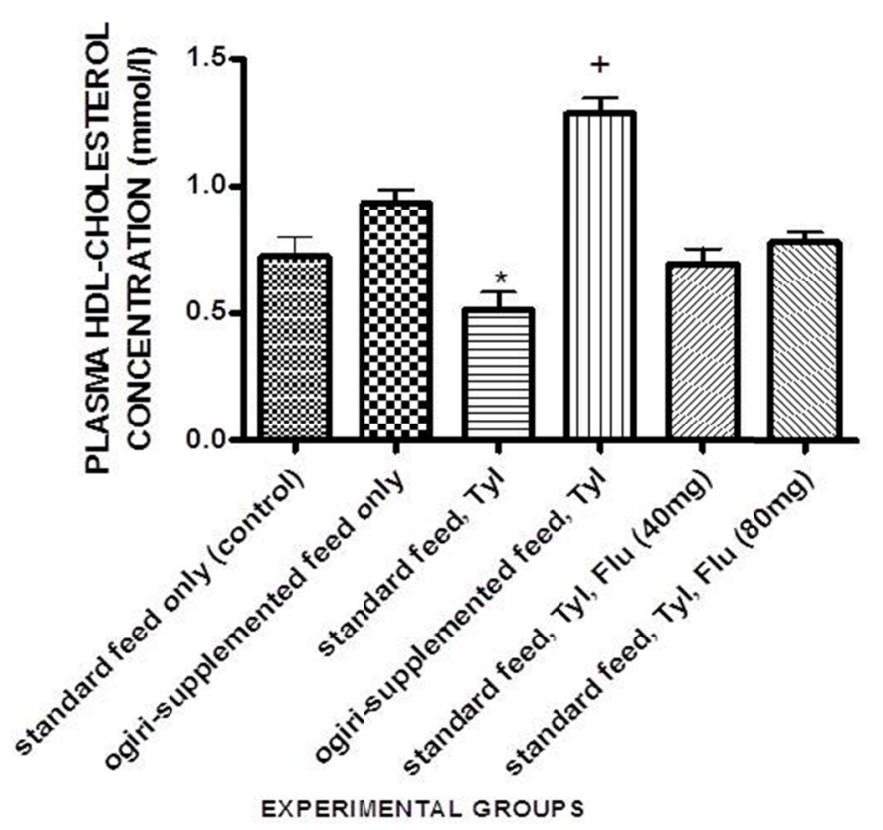

Figure 5. Graph showing the effect of rat feed and treatment(s) on plasma HDL-C concentration following tyloxapol-induced hyperlipidaemia. $n=5$. (Tyl- Tyloxapol; Fluv-Fluvastatin sodium, HDL-C- High density lipoprotein cholesterol)

The liver homogenates lipid profile analyses (Table 1) revealed a significant increase $(P<0.05)$ in TC and TG due to tyloxapol administration. This increase was again mitigated in fermented Citrullus vulgaris (FCV) and fluvastatin pre-treated experimental rats. Pre-treatment of rats with the supplemented feed resulted in a significant decrease $(P<0.05)$ in TC and TG values. $40 \mathrm{mg}$ fluvastatin gave rise to significant reduction in TC and TG levels, the rates of reduction however were not sustained at the higher dose of fluvastatin. Again, OSF 
pre-fed rats gave statistically significant $(\mathrm{P}<0.05)$ increase in HDL-C values with tyloxapol administered. Fluvastatin at both concentrations gave higher values compared with OSF.

Table 1. Values of liver homogenates' lipid profile estimation

\begin{tabular}{cccc}
\hline Treatment groups & $\begin{array}{c}\text { HDL-Cholesterol } \\
(\mathrm{mmol} / \mathrm{l})\end{array}$ & $\begin{array}{c}\text { Triglyceride } \\
(\mathrm{mmol} / \mathrm{l})\end{array}$ & $\begin{array}{c}\text { Total Cholesterol } \\
(\mathrm{mmol} / \mathrm{l})\end{array}$ \\
\hline Standard feed only (control) & $0.332 \pm 0.02$ & $1.628 \pm 0.13$ & $1.237 \pm 0.14$ \\
Ogiri-supplemented feed & $0.340 \pm 0.02$ & $1.751 \pm 0.08$ & $0.937 \pm 0.02$ \\
Standard feed+ tyloxapol & $0.265 \pm 0.03$ & $2.253 \pm 0.09$ & $2.328 \pm 0.07$ \\
Ogiri-supplemented feed +tyloxapol & $0.598 \pm 0.06$ & $1.722 \pm 0.09$ & $1.800 \pm 1.04$ \\
Standard feed+tyloxapol+fluvastatin & $0.722 \pm 0.02$ & $1.247 \pm 0.07$ & $1.183 \pm 0.05$ \\
$\begin{array}{c}\text { (40 mg) } \\
\text { Standard feed+tyloxapol+fluvastatin } \\
\text { (80 mg) }\end{array}$ & $0.914 \pm 0.11$ & $1.745 \pm 0.04$ & $1.658 \pm 0.07$ \\
\hline
\end{tabular}

Values are expressed as Mean \pm SEM of duplicate readings. $\mathrm{P}<0.05$ was considered significant.

\subsection{Antioxidant Activities}

The condiment showed considerable antioxidant potentials (Table 2) in comparison with the reference antioxidant agents used. Activities were concentration dependent, i.e., the higher the sample concentration, the greater the antioxidant activity.

Table 2. Antioxidant assay results

\begin{tabular}{cccccccc}
\hline \multicolumn{2}{c}{ DPPH } & \multicolumn{2}{c}{ Nitric oxide } & \multicolumn{2}{c}{ Anti-lipid peroxidation } & \multicolumn{2}{c}{ Ascorbic acid equivalent } \\
$\begin{array}{c}\text { Conc. } \\
(\mathrm{mg} / \mathrm{ml})\end{array}$ & $\begin{array}{c}\% \\
\text { inhibition }\end{array}$ & $\begin{array}{c}\text { Conc. } \\
(\mathrm{mg} / \mathrm{ml})\end{array}$ & $\begin{array}{c}\% \\
\text { inhibition }\end{array}$ & $\begin{array}{c}\text { Conc. } \\
(\mathrm{mg} / \mathrm{ml})\end{array}$ & \% inhibition & $\begin{array}{c}\text { Conc. } \\
(\mathrm{mg} / \mathrm{ml})\end{array}$ & $\begin{array}{c}\text { \% inhibition } \\
(\mu \mathrm{gVitCeqv} / \mathrm{g})\end{array}$ \\
\hline 25.00 & $52.32 \pm 2.17$ & 100.00 & $42.39 \pm 1.05$ & 100.00 & $18.94 \pm 0.02$ & 100.00 & 0.64 \\
12.50 & $29.54 \pm 2.01$ & 50.00 & $37.96 \pm 0.84$ & 50.00 & $10.57 \pm 3.16$ & 50.00 & 0.95 \\
6.25 & $23.78 \pm 3.16$ & 25.00 & $36.09 \pm 1.07$ & 25.00 & $4.22 \pm 0.20$ & 25.00 & 0.81 \\
3.12 & $1.48 \pm 0.18$ & 12.50 & - & 12.50 & & 12.50 & \\
IC50 & 23.05 & 35.26 & 17.41 & 35.26 & & &
\end{tabular}

Values are mean \pm SEM of triplicate readings. Conc.- (concentration); $\mu \mathrm{g}$ VitCeqv/g- (unit of standard Vitamin C used for the assay. i.e. microgram vitamin $\mathrm{C}$ equivalent per gram); $\mathrm{mg} / \mathrm{ml}$ - milligram per milliliter.

\subsection{Liver Sections Examined}

Histomicrographs examination revealed necrosed hepatocytes with poorly defined sinusoids in between the plates in the liver section of group C rats. However, in the FCV pre-treated rats, the liver sections appeared normal. Fluvastatin treated groups also showed nearly normal liver sections. Group E rat hepatocytes appeared normal with visible portal area. Hepatocytes of group F liver section also appeared normal. The hepatocytes are arranged in plates around the central vein with sinusoids in between the plates. The architecture of the liver of the condiment supplemented groups and standard group rats appear normal. The hepatocytes are arranged in plates around the central vein with sinusoids in between the plates (pictures not presented here).

\section{Discussion}

Fermented foods have been established to possess improved nutritional content (Odunfa, 1981; Omafuvbe et al., 2004; Ognatan et al., 2011). Ogbonnaya et al., (Ogbonnaya, Orhevba, \& Babatunde 2010), reported an increase in lipids, crude protein and certain minerals content due to fermentation in Parkia biglobosa seeds, a condiment used in a similar way to FCV. FCV is undoubtedly enriched with nutrients and hence triggered improved growth 
in fed animals (Figure 1). Gadaga et al., (Gadaga, Nyanga, \& Mutukumira 2004), also reported improvement of nutritional value and protection against bacterial pathogens in food as a result of fermentation.

Tyloxapol - a chemical detergent was used to produce hyperlipidaemia in rats in this study. Its mechanism of action is known to accelerate the hepatic cholesterol synthesis in phase I (after 24-hour tyloxapol injection) (Ngoc et al., 2008). Tyloxapol in this study, in agreement with literature (Otway \& Robinson, 1967; Abe et al., 2007), induced significant increase in TC and TG, evident in the liver cell sections.

This increase was abrogated as a result of pre-treatment of rats with the FCV condiment-composed diet. The condiment was effective in mitigating increased TC concentration, even better than at both concentration of the reference drug used in the study. Fermented Parkia biglobosa seeds showed similar observation when fed to tyloxapol-induced hyperlidaemic rats (Ayo-Lawal et al., 2014). The result of this study further showed that the condiment caused a significant $(\mathrm{P}<0.05)$ increase in the plasma level of HDL-C, which is described as 'good cholesterol' (Agbedana, 1999). The combined effects of increased HDL-C and decreased LDL-C (bad cholesterol) resulted in an increased HDL-C/LDL-C ratio in the test animals. This suggests that supplementation of diet with the condiment might lead to a reduction in the risk of developing heart diseases, because a high HDL-C/LDL-C ratio has been shown to be beneficial and is indicative of a lower risk of coronary heart diseases (Castelli, 1984). Again, it has been repeatedly reported that the higher the level of LDL cholesterol, the greater the risk of atherosclerotic heart disease conversely the higher the level of HDL cholesterol the lower the risk of coronary heart disease (Grundy, 1986; LaRosa et al., 1990).

There is a remarkable advantage in feeding with FCV over synthetic drug in this study. Treatment with fluvastatin sodium resulted in an HDL-C/LDL-C ratio that was lower than the value obtained from condiment-fed rats. Ngoc et al. (2009), also reported greater reduction in lipid profile from Abelmoschus esculentus extracts compared with the standard drug - simvastatin used in their study. The hypolipidaemic effect observed in plasma lipids and lipoproteins may also not be unconnected with the presence of the natural phytoconstituents in the seeds and others resulting from fermentation. From the results obtained for liver homogenates, this study established hepatoprotective effects of the condiment (Table 1).

Histopathologically, it has been reported that administration of tyloxapol tends to damage the liver cells by reducing the activity of liver lipogenesis dehydrogenase (Silva et al., 2001). In this study, administration of 250 $\mathrm{mg} / \mathrm{kg}$ body weight of tyloxapol induced liver cells degeneration, fibrosis and necrosis which were not found in groups pre-fed with the FCV-composed feed. This again suggests that regular intake of the condiment might possess hepatoprotective effect.

In view of the fact that diet and/or drug administration have been identified as a major way of preventing or treating many disorders linked with hyperlipidaemia and lipid disorders generally (Marie \& Vladim, 2001; Grundy et al., 2004), the findings from this study is of extreme importance.

\section{Conclusion}

In conclusion, diets formulated with fermented Citrullus vulgaris seeds have hypolipidaemic activity in tyloxapol-induced hyperlipidaemia in rats. The condiment may be useful in lowering cholesterol and triglycerides levels in hyperlipidaemia. Further studies in others animal species and in other hyperlipidaemic model are required to elucidate its hypolipidaemic activity. Long term toxicity tests at greater concentrations are also recommended. However, consumption of fermented Citrullus vulgaris seeds is recommended in humans based on the results of this study.

\section{Abbreviations:}

FCV, fermented Citrullus vulgaris; LDL-C, low density lipoprotein cholesterol; HDL, High density lipoprotein cholesterol; TC, Total Cholesterol; TG, Triglycerides; OSF, ogiri-supplemented Feed; DPPH, 2,2-Diphenyl-1picrylhydrazyl;

\section{Acknowledgements}

The authors would like to thank Dr. Adeyemi David, of the Department of Anatomy and Cell Biology, Obafemi Awolowo University, Ile-Ife, Osun State, Nigeria for assistance with the histomorphological studies.

\section{References}

Abe, C., Ikeda, S., Uchida, T., Yamashita, K., \& Ichikawa, T. (2007). Triton WR1339, an inhibitor of lipoprotein lipase decreases Vitamin E concentration in some tissues of rats by inhibiting its transport to liver. $J$. Nutr, $137,345-350$.

Achi, O. K. (2005). Traditional fermented protein condiments in Nigeria. Afr. J. Biotechnol, 4(13), 1612-1621. 
Agbedana, E. O. (1999). Cholesterol and your health. Inaugural Lecture Delivered at the University of Ibadan, John Archers Publication, Ibadan.

Agriculture and consumer protection (ACP) in FAO Corporate Document Repository. Fermented Fruits and Vegetables. A Global perspectives. www.fao.org/docrep/x0560E/x560E00.htm

Ajayi, O. B., \& Ajayi, D. D. (2009). Effect of oilseed diets on plasma lipid profile in albino rats. Pak. J. Nutr, 8, 116-118. http://dx.doi.org/10.3923/pjn.2009.116.118

Akinyele, B. J., \& Oloruntoba, O. S. (2013). Comparative Studies on Citrullus vulgaris, Citrullus colocynthis and Cucumer opsismannii for Ogiri Production. British Microbiology Research Journal, 3(1), 1-18. http://dx.doi.org/10.9734/BMRJ/2013/2337

Ansarullah, J. R. N., Thounaojam, M. C., Patel, V., Devkar, R. V., \& Ramachandran, A. V. (2009). Antihyperlipidemic potential of a polyherbal preparation on tyloxapol WR 1339 (Tyloxapol) induced hyperlipidemia: A comparison with lovastatin. Int. J. of Green Pharm, 3, 119-124. http://dx.doi.org/10.4103/0973-8258.54900

Ayo-Lawal, R. A., Osoniyi, O., Famurewa, A. J., \& Lawal, O. A. (2014). Evaluation of antioxidant and hypolipidaemic effects of fermented Parkia biglobisa (Jacq) seeds in tyloxapol-induced hyperlipidaemic rats. Afr J Fd Sc, 8(5), 225-232. http://dx.doi.org/10.5897/AJFS2013.1124

Benzie, I. F. F., \& Strain, J. J. (1999). Ferric reducing/antioxidant power assay: Direct measure of total antioxidant activity in biological fluids and modified version for simultaneous measurement of total antioxidant power and ascorbic acid concentration. Methods Enzymol, 299, 15-27. http://dx.doi.org/10.1016/s0076-6879(99)99005-5

Blois, M. S. (1958). Antioxidant determinations by the use of a stable free radical. Nature, 181, 199-200. http://dx.doi.org/10.1038/1811199a0

Boros, L. G., Nichelatti, M., \& Shoenfeld, Y. (2005). Fermented wheat germ extract (Avemar) in the treatment of cancer and autoimmune diseases. Ann $N \quad Y$ Acad Science, 1051, 529-542. http://dx.doi.org/10.1196/annals.1361.097

Castelli, L. (1984). Epidemiology of coronary heart disease. Am. J. Med, 76, 4-12. http://dx.doi.org/10.1016/0002-9343(84)90952-5

Damjana, R., \& Katalin, M. (2010). Perspectives of the non-statin hypolidemicagents. Pharmacol. and Ther, 127, 19-40. http://dx.doi.org/10.1016/j.pharmthera.2010.03.007

Drury, R. A. B., \& Wallington, E. A. (1980). Carleton's histological technique. Oxford: Oxford University Press.

Edem, D. O. (2002). Palm oil: Biochemical, physiological aspects, a review. Plant foods Hum.Nutr, 57, 319-341. http://dx.doi.org/10.1023/A:1021828132707

Edionwe, A. O., \& Kies, C. (2001). Comparison of palm and mixtures of refined palm and soyabean oils on serum lipids and faecal fat and fatty acid excretion of adult humans. Plant foods Hum. Nutr., 56, 157-165. http://dx.doi.org/10.1023/A:1011136724577

Friedwald, W. T., Levy, R. I., \& Fredicksm, D. (1972). Estimation of low-density lipoprotein cholesterol without the use of the preparative ultracentrifuge. Clin Chem, 18, 499-502.

Gadaga, T. H., Nyanga, L. K., \& Mutukumira, A. N. (2004). The occurrence, growth and control of pathogens in African fermented foods. Afr. J Fd Agric. Nutr. and Devpt, 4, 20-23.

Grundy, S. M. (1986). Comparison of monounsaturated fatty acids and carbohydrates for lowering plasma cholesterol. New Engl. J. Med, 314, 745-748. http://dx.doi.org/10.1056/NEJM198603203141204

Grundy, S. M. (2013). Statin discontinuation and intolerance. The challenge of lifelong therapy. Ann Intern med. 158, 562-563. http://dx.doi.org/10.7326/0003-4819-158-7-201304020-00010

Grundy, S. M., Cleeman, J. I., Merz, C. N., Brewer, H. B. Jr, Clark, L. T., \& Hunningghake, D. B. (2004). Implications of recent clinical trials for the National cholesterol education program adult treatment panel III guidelines. Circulation, 110, 227-239. http://dx.doi.org/10.1161/01.CIR.0000133317.49796.0E

Kamisah, Y., Adam, A., WanNgah, W. Z., Gapor, M. T., Azizah, O., \& Merzuki, A. (2005). Chronic intake of red palm oil and palm olein produced beneficial effects on plasma lipid profile in rats. Pak J. Nutr, 4, 89-96. http://dx.doi.org/10.3923/pjn.2005.89.96

LaRosa, J. C., Hunninghake, D., Bush, D., Criqui, M. H., Getz, G. S., \& Gotto, A. M. (1990). The cholesterol 
facts. Circulation, 81, 1721-1733. http://dx.doi.org/10.1161/01.CIR.81.5.1721

Lewington, S., Whitlock, G., Clarke, R., Sherliker, P., Emberson, J., Halsey, J., ... Collins, R. (2007). Blood cholesterol and vascular mortality by age, sex, and blood pressure: A meta- analysis of individual data from 61 prospective studies with 55,000 vascular deaths. Lancet, 370, 1829-1839. http://dx.doi.org/10.1016/S0140-6736(07)61778-4

Marcocci, L., Packer, L., \& Droy-Lefaix, M. T. (1994). Antioxidant action of Gingkobiloba extracts EGb761. Methods Enzymol, 234, 462-475.

Marie, C., \& Vladim V. (2001). Effects of high-fat and Chlorella vulgaris feeding on changes in lipid metabolism in mice. Biologia Bratislava, 656-661.

Nabasree, D., \& Bratati, D. (2002). Antioxidant activity of Piper betel L. leaf extract in vitro. Food Chemistry, 88, 19-224.

Ngo, T. H., Ngoc, O. N., Van, A. T., \& Phung, N. V. (2008). Hypolipidemic effect of extracts from Abelmoschus esculentus L (Malvaceae) on tyloxapol-induced hyperlipidemia in mice. Mahidol University Journal of Pharmaceutical Sciences, 35, 42-46.

Odetola, A. A., Akinloye, O., Egunjobi, C., Adekunle, W. A., \& Ayoola, A. O. (2006). Possible antidiabetic and antihyperlipidaemic effect of fermented Parkiabiglobosa (Jacq) extract in alloxan-induced diabetic rats. Clin. Exp. Pharmacol and Physiol, 33, 808-812. http://dx.doi.org/10.1111/j.1440-1681.2006.04444.x

Odunfa, S. A. (1981). Microbiology and amino acids composition of ogiri a food condiment from fermented melon seeds. Die Nahrung, 25, 811-813. http://dx.doi.org/10.1002/food.19810250903

Ogbonnaya, C., Orhevba, B. A., \& Babatunde, I. M. (2010). Influence of Hydrothermal Treatments on Proximate Compositions of Fermented Locust Bean (Dawadawa). J. Food Technol, 8, 99-101. http://dx.doi.org/10.3923/jftech.2010.99.101

Ognatan, K., Adi, K., Lamboni, C., Damorou, J-M., Aklikokou, K. A., Gbeassor, M., \& Guilland, J-C. (2011). Effect of dietary intake of fermented seeds of Parkiabiglobosa (Jacq) Benth (African Locust Bean) on hypertension in Bogou and Goumou-kope areas of Togo. Trop. J. Pharm. Res, 10, 603-609.

Omafuvbe, B. O., Falade, S. O., Osuntogun, B. O., \& Adewusi, S. R. A. (2004). Chemical and biochemical changes in African Locust Bean (Parkia biglobosa) and Melon (Citrullus vulgaris) Seeds during fermentation to condiments. Pak. J. Nutr, 3, 140-145. http://dx.doi.org/10.3923/pjn.2004.140.145

Otway, S., \& Robinson, D. S. (1967). The effect of a non-ionic detergent (Triton WR-1339) on the removal of triglyceride fatty acids from the blood of the rat. $J$ Physiol, 190, 309-319. http://dx.doi.org/10.1113/jphysiol.1967.sp008210

Rosebaum, D., Dallongeville, J., Sabouret, P., \& Bruckert, E. (2012). Discontinuation of statin therapy due to muscular side effects: A survey in real life. NutrMetab and Cardiovasc Dis, 10, 4-12.

Ross, R. (1999). Atherosclerosis an inflammatory disease. N. Engl. J., 340, 115-126. http://dx.doi.org/10.1056/NEJM199901143400207

Silva, R. M., Santos, F. A., Maciel, M. A., Pinto, A. C., \& Rao, V. S. (2001). Effect of transdehydrocrotonin, a 19-nor-clerodane diterpene from Croton cajucara on experimental hypertriglyceridaemia and hypercholesterolaemia induced by Triton WR 1339 (tyloxapol) in mice. Planta Med, 67, 763-765. http://dx.doi.org/10.1055/s-2001-18360

Steinkraus, K. H. (1995). Handbook of Indigenous Fermented Foods. New York, Marcel Dekker, Inc.

Sultan, S., \& Hynes, N. (2013). The ugly side of statins. Systemic appraisal of the contemporary unknown unknowns. OJEMD, 3, 179-185. http://dx.doi.org/10.4236/ojemd.2013.33025

\section{Copyrights}

Copyright for this article is retained by the author(s), with first publication rights granted to the journal.

This is an open-access article distributed under the terms and conditions of the Creative Commons Attribution license (http://creativecommons.org/licenses/by/3.0/). 